\title{
Obstructive Fibrinous Tracheal Pseudomembrane: A Rare Condition in Postextubation Stridor
}

\author{
Narongwit Nakwan MD
}

\begin{abstract}
Obstructive fibrinous tracheal pseudomembrane (OFTP) is an airway complication that occurs after endotracheal intubation. It originates from superficial mucosal abrasion and desquamation of necrotic tracheal epithelium at the site of cuff pressure. This condition is a rare cause of postextubation stridor. We present a case of postextubation stridor secondary to OFTP, resulting in clinical features of upper airway obstruction $>8 \mathrm{~h}$ after extubation. The case features complete obstruction at the tip of the endotracheal tube from OFTP. Key words: stridor; acquired subglottic stenosis; tracheal disease. [Respir Care 2014;59(7):e91-e93. () 2014 Daedalus Enterprises]
\end{abstract}

\section{Introduction}

Postextubation stridor is a life-threatening condition. Causes include obstruction with secretions, vocal cord edema, vocal cord dysfunction, and tracheomalacia. ${ }^{1}$ This report describes a rare case of postextubation stridor due to obstructive fibrinous tracheal pseudomembrane (OFTP) that blocked the tip of an endotracheal tube (ETT), requiring re-intubation.

\section{Case Report}

A 29-y-old man was admitted with respiratory failure and diabetic ketoacidosis. Five days before admission, he presented with fever, productive cough, and worsening shortness of breathing. He had a 15 pack-year smoking history and continued to smoke 8-10 cigarettes per day. On the first day of admission, he developed respiratory failure, requiring endotracheal intubation with low-pressure high-volume ETT, and was transferred to the ICU for

The author is affiliated with the Division of Pulmonology, Department of Medicine, Hat Yai Medical Education Center, Hat Yai Hospital, Songkhla, Thailand.

The author has disclosed no conflicts of interest.

Correspondence: Narongwit Nakwan MD, Division of Pulmonology, Department of Medicine, Hat Yai Medical Education Center, Hat Yai Hospital, Songkhla 90110, Thailand. E-mail: naronak@ hotmail.com.

DOI: $10.4187 /$ respcare. 02857 ventilatory support and hemodynamic monitoring. Physical examination revealed a temperature of $39^{\circ} \mathrm{C}$, cyanosis, and bilateral inspiratory fine crackles over the lower lung zones. Chest radiograph revealed opacification predominately in the right upper lobe and right lower lobe areas, consistent with pneumonia. He was treated with broadspectrum antibiotics and intravenous insulin infusion. In the ICU, the endotracheal cuff pressure was checked routinely and adjusted to be $<25 \mathrm{~cm} \mathrm{H}_{2} \mathrm{O}$. He was removed from mechanical ventilation $10 \mathrm{~d}$ after admission; however, $8 \mathrm{~h}$ after extubation, he complained of dyspnea, and examination revealed inspiratory stridor. Direct laryngoscopy was performed and revealed no evidence of angioedema or vocal cord dysfunction. His clinical picture worsened, and the subject was re-intubated. However, ventilation was not possible due to significantly elevated airway pressure. Suction through the ETT was not attempted due to severe restlessness and oxygen desaturation. The ETT was immediately removed. At the tip of the ETT, there was a tubular membrane of necrotic debris $(\sim 3 \mathrm{~cm}$ long and $1.5 \mathrm{~cm}$ thick) (Figs. 1 and 2). This membrane completely obstructed the tip of the ETT. His stridor resolved immediately after ETT removal within a few minutes. Repeat bronchoscopy was considered to demonstrate residual tissue and tracheal mucosa. Unfortunately, the subject absolutely refused any additional procedures. He was closely observed for any respiratory compromise over a period of $24 \mathrm{~h}$ without any further need for re-intubation. Histopathology of the necrotic debris revealed membranous fragments of fibrino-inflammatory debris with focal areas of reactive squamous epithelium. 


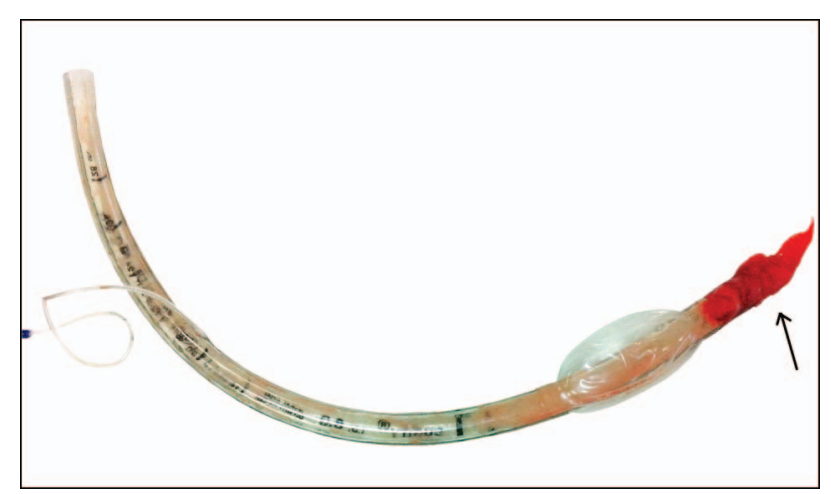

Fig. 1. Necrotic debris completely obstructing the tip of the endotracheal tube (arrow).

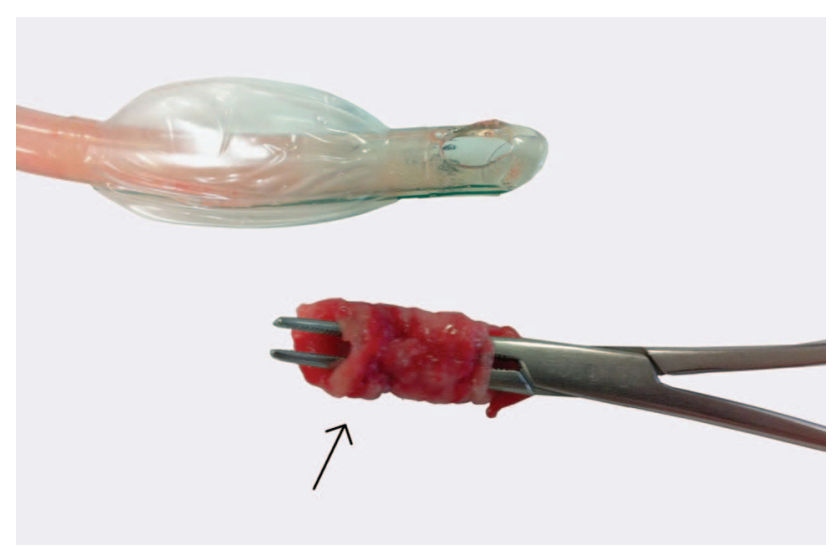

Fig. 2. A thick, circular, rubber-like pseudomembrane (arrow) was revealed.

\section{Discussion}

Several etiologies of postextubation stridor have been described. OFTP is a rare cause of this condition. We presented a case of a worsening dyspnea and inspiratory stridor in the postextubation period, with OFTP diagnosed by observation of a thick, reddish/whitish, tubular pseudomembrane molding within the tip of the ETT, leading to complete luminal obstruction.

Postintubation tracheal complication is a result of airway damage, with the most common entities being tracheal stenosis and tracheomalacia, ${ }^{2}$ whereas OFTP is rare and little known. Etiologically, high endotracheal cuff pressure leads to local ischemia, subsequent infarction, and ultimately necrosis of the tracheal mucosa. ${ }^{2}$ It is postulated that OFTP may be the initial process that can lead to tracheal stenosis afterwards. ${ }^{3}$ This process results in superficial tracheal damage, leading to a macroscopic visible tissue plug at the site of the endotracheal tube cuff. Pathological findings include superficial abrasions of the mucosa and desquamated necrotic tracheal epithelium. ${ }^{2} \mathrm{Sev}-$ eral factors have been proposed that predispose patients to tracheal injury after intubation ${ }^{4}$; however, the risk factors for OFTP remain difficult to ascertain due to the rarity of the condition. We postulate that diabetes may have been a contributing factor to the development of OFTP in this subject, as microcirculatory changes in diabetes that are well described may directly affect tissue healing.

Diagnosis of OFTP can be challenging because clinicians are often misled to diagnose patients with other causes of postextubation stridor. We believe that positional and intermittent stridor due to ball-valve obstruction from the pseudomembrane may be an important clinical clue. Onset of respiratory distress in OFTP varies, ranging from within the first hour to $14 \mathrm{~d}$ after extubation. ${ }^{3,5-9}$ The type of ETT may directly affect development of OFTP; however, we have no explanation as to why OFTP still occurred in our subject despite the fact that a low-pressure high-volume cuff was used in conjunction with intensive monitoring of cuff pressure.

Early detection of OFTP is important to avoid further deterioration of a patient. However, diagnosis of this condition remains difficult. A recent report suggested that flexible or rigid bronchoscopy appears to be of value diagnostically and may also allow removal of the lesion. ${ }^{5}$ Macroscopically, bronchoscopy usually reveals a thick, circular, rubber-like membrane adhering to the tracheal wall at the site of the cuff. However, our subject was surprisingly diagnosed with a visible pseudomembrane blocking the ETT lumen. We suppose that re-intubation may have detached the tissue from the tracheal wall. Unfortunately, repeat bronchoscopy was not performed to evaluate the residual tissue and tracheal mucosa due to the subject's refusal. However, in most cases, OFTPs are easily removed by bronchoscopy, and patients almost always recover without residual lesions. ${ }^{7-9}$ In addition to bronchoscopy, chest imaging, particularly chest computed tomography, is also helpful in diagnosing OFTP. ${ }^{8,9}$ Occasionally, this condition may be diagnosed by spontaneous expectoration of the OFTP tissue. However, prompt recognition of this condition is vital, as management of the patient will be completely altered.

\section{Conclusion}

In conclusion, this report highlights OFTP as a potentially fatal condition in patients presenting with dyspnea and postextubation stridor. Clinicians should be aware of this condition, and bronchoscopy should be performed to allow early detection.

\section{REFERENCES}

1. Wittekamp BH, van Mook WN, Tjan DH, Zwaveling JH, Bergmans DC. Clinical review: post-extubation laryngeal edema and extubation failure in critically ill adult patients. Crit Care 2009;13(6):233. 


\section{Obstructive Fibrinous Tracheal Pseudomembrane}

2. Wain JC. Postintubation tracheal stenosis. Semin Thorac Cardiovasc Surg 2009;21(3):284-289.

3. Deslée G, Brichet A, Lebuffe G, Copin MC, Ramon P, Marquette $\mathrm{CH}$. Obstructive fibrinous tracheal pseudomembrane. A potentially fatal complication of tracheal intubation. Am J Respir Crit Care Med 2000;162(3):1169-1171.

4. Santos PM, Afrassiabi A, Weymuller EA Jr. Risk factors associated with prolonged intubation and laryngeal injury. Otolaryngol Head Neck Surg 1994;111(4):453-459.

5. Lins M, Dobbeleir I, Germonpré P, Waelput W, Pauwels P, Jorens PG. Postextubation obstructive pseudomembranes: a case series and review of a rare complication after endotracheal intubation. Lung 2011;189(1):81-86
6. Rice BL, Culver DA, Santacruz JF, Lazar CA, McCarthy K, Gildea TR. Obstructive fibrinous tracheal pseudomembrane. Ann Thorac Surg 2011;92(6):e115-e117.

7. Fiorelli A, Vicidomini G, Messina G, Santini M. Spontaneous expectoration of an obstructive fibrinous tracheal pseudomembrane after tracheal intubation. Eur J Cardiothorac Surg 2011;40(1):261263.

8. Yildirim BB, Karalezli A, Hasanoglu HC, Kandemir O. Obstructive fibrinous tracheal pseudomembrane. J Bronchology Interv Pulmonol 2012;19(2):129-131

9. Patolia S, Enriquez D, Schmidt F, Quist J. Obstructive fibrinous tracheal pseudomembrane. J Bronchology Interv Pulmonol 2013; 20(1):63-65. 